\title{
Representações geo-histórias de Minas Gerais por meio da Cartografia
}

\author{
Geohistorical representations from Minas Gerais through Cartography
}

\author{
Regina Gonçalves Bastos \\ Geógrafa e Mestra em Geografia pelo Programa de Pós Graduação em Geografia \\ Tratamento da Informação Espacial, PUC Minas, Brasil \\ reginagb127@hotmail.com \\ Winnie Parreira Patrocínio \\ Geógrafa pela Pontifícia Universidade Católica de Minas Gerais, PUC Minas \\ Pós-graduanda - Especialização em Ensino de Geografia pela \\ Universidade Federal dos Vales do Jequitinhonha e Mucuri (UFVJM), Brasil \\ winnieparreira@gmail.com
}

\begin{abstract}
Resumo
O trabalho apresenta as representações geográficas e históricas do Estado de Minas Gerais, através da construção de uma linha do tempo com mapas históricos que evidenciam a historicidade do estado. Para isso, utilizou-se o aporte teórico que contém categorias de análise geográfica, como Território; o contexto histórico de Minas Gerais; e a análise dos mapas selecionados para a produção, revelando a influência política da produção cartográfica nos seus diversos usos.
\end{abstract}

Palavras-chave: Geografia Histórica, Cartografia Histórica, Linguagem Cartográfica

\begin{abstract}
This work presents geographic and historical representations of the State of Minas Gerais, through the construction of a timeline with historical maps that evidence the historicity of the state. For this, the theoretical contribution that contains categories of geographic analysis was used, as Territory; the historical context of Minas Gerais; and an analysis of the selected maps for this production, revealing a political influence of the cartographic production in its diverse uses.
\end{abstract}

Keywords: Historical Geography, Historical Cartography, Cartographic Language.

\section{INTRODUÇÃO}

O estado de Minas Gerais apresenta sua história marcada por interesses econômicos e políticos que moldaram seu território. Vivenciando diversos conflitos, a unidade administrativa passou por muitas transformações. Na Cartografia, esses interesses são refletidos nas representações que são movidas por concepções ideológicas, com interpretações e interesses individuais.

A análise dos mapas sempre foi fundamental para refletir sobre o contexto histórico de um lugar e em uma determinada época, tanto de aspectos físicos e socioeconômicos, como interesses e necessidades de quem vivia no período.

Com essa orientação, a justificativa para o desenvolvimento desta pesquisa consiste em demonstrar como a análise cartográfica revela a história de Minas Gerais. A perspectiva geográfica 
e a percepção do espaço serão observadas na produção territorial, especialmente os interesses de quem produziu os mapas, e a finalidade. Outra contribuição dessa análise consiste na interpretação política de uma época e as mesmas variações cartográficas em um recorte temporal.

Assim, a história de Minas Gerais é aqui evidenciada a partir de suas representações cartográficas, analisando as formas conflituosas de demarcar um território e demonstrar o poder, em uma região que revela riquezas minerais e sua extensa rede hidrográfica, condições fundamentais para o desenvolvimento econômico.

Os bandeirantes marcaram o início do povoamento em Minas Gerais em função das riquezas minerais. O povoamento se inicia entre 1601 e 1602 (LIMA JUNIOR, 1978) quando a região recebeu os exploradores. Segundo o referido autor, a ocupação foi um processo lento, que aos poucos foi se intensificando e causando variados impactos, com desequilíbrios tanto do ambiente natural como das relações comerciais e controle administrativo.

A relação do território do ouro é um aspecto fundamental para o povoamento e produção cartográfica dessas localidades. A discussão territorial é um aspecto chave para a análise e estudo das representações cartográficas, nesse caso em Minas Gerais. Considerando os diversos processos nos quais Minas Gerais estava submetida - expansão do território e definição dos seus limites, desequilíbrios na economia, distribuição demográfica em transformação - assim como as tensões no âmbito nacional que vieram transformar o Brasil Imperial, a necessidade em avançar com o controle territorial se fazia presente.

Diante do acervo bibliográfico e cartográfico de Minas Gerais dos séculos XVIII e XIX, surge a questão norteadora: as reproduções cartográficas revelam a historicidade de Minas Gerais? A partir disso, foi construída a hipótese: a linguagem cartográfica é influenciada e produzida a partir de interesses políticos.

Essa pesquisa tem por objetivo geral, analisar, a partir da linguagem cartográfica, a reprodução histórica do estado de Minas Gerais desde sua origem até os dias atuais. Para se atingir tal objetivo, foram elencados alguns objetivos específicos: desenvolver aporte teórico referente às categorias geográficas convenientes para o processo (em que foram elaboradas a discussões sobre território e poder, as representações cartográficas e a Geografia Histórica); descrever o contexto histórico (dividido entre a descoberta do ouro, a decadência do ouro e a expansão territorial de Minas Gerais); identificar os métodos de registro cartográfico em Minas Gerais ao longo da afirmação do estado; e argumentar a influência política dos registros cartográficos.

O capítulo de resultados possui a descrição dos mapas, destacando os métodos de registro cartográfico e as representações concentradas na maioria dos mapas. Esses mapas foram selecionados a partir da motivação de acontecimentos destacados na historicidade. 
Com a descrição, há a análise em uma abordagem política. Para isso foram evidenciadas as prioridades em representação. Os dilemas nos limites estaduais mostram também a incoerência em mapas produzidos em um mesmo contexto histórico por autores diferentes.

As considerações finais trazem as reflexões ao longo do trabalho, confirmando a hipótese da posição política que o mapa exerce ao representar o território, contextualizada em Minas Gerais, estado apreciado e palco de conflitos marcantes que revelam suas potencialidades.

\section{METODOLOGIA}

Como metodologia do trabalho, foi utilizada primeiramente a consulta a autores chaves da ciência geográfica para basearmos o referencial teórico e realizar a reflexão necessária para a concretização da pesquisa. Foi feita a conceituação de Território, Representações Cartográficas, Cartografia Histórica e Geografia Histórica. Além disso, também foram realizadas consultas a fontes primárias e fontes secundárias para a pesquisa sobre o contexto histórico econômico, social e físico do contexto mineiro a partir do século XVI, onde configurações territoriais e espaciais sofreram bruscas mudanças e é de fundamental importância o seu entendimento para assim estudar a sua cartografia.

Foi utilizado o método desenvolvido por Castro (2013) de georreferenciamento e cartometria de mapa histórico no desenvolvimento da pesquisa; especialmente a superposição de camadas de informação, os deslocamentos de vetores e as distorções da grade em relação ao mapa atual de Minas Gerais. Também houve mapas históricos que foram encontrados via Internet, acervos e livros. Em alguns deles, foram utilizados recursos da cartografia digital, do georreferenciamento e a sobreposição dos limites atuais de Minas Gerais com o limite dos mapas históricos do século XVIII e do século XIX, com o fim de demonstrar e analisar o território mineiro e suas mudanças no decorrer do século.

Os mapas de José Joaquim da Rocha estavam com as coordenadas no meridiano da Ilha de Ferro e foram georreferenciados para converter este para o meridiano de Greenwich, pelo software ArcGIS. No mapa de José Joaquim da Rocha de 1778, onde se tem o limite inteiro da Capitania de Minas Gerais, foi feito a sobreposição de limites com o atual limite da Unidade da Federação e o georreferenciamento para a adequação ao meridiano de Greenwich. Nos outros mapas de José Joaquim da Rocha foi feito o mesmo processo de georreferenciamento, sobreposição de camadas de informação para a análise dos limites do mapa histórico com o mapa atual da unidade de federação, e, além disso, foi feito separadamente para cada um dos quatro mapas das comarcas de Minas Gerais: Sabará, Serro Frio, Vila Rica e Rio das Mortes. 
Após isso, foi realizada uma vetorização para cortar essas áreas de seus mapas iniciais, e colocá-las sobrepondo as camadas de informação para serem observados os erros de longitude, escala, projeção e também os acertos e de que forma esses limites se assemelham com os limites atuais provando que mesmo separadamente eles conseguiam representar bem o território mineiro, principais cursos d'águas, etc.

Aliando a produção cartográfica da época ao seu contexto, o mesmo método de Castro (2013) foi utilizado no mapa de Eschwege em 1826. Diferentemente dos mapas do Rocha; o referido em questão utilizou o meridiano do Rio de Janeiro para cartografar seu mapa. Foi feito o georreferenciamento e adequação para o atual meridiano de Greenwich e a sobreposição das camadas de informação com o atual limite do estado.

Assim, os métodos derivam entre a utilização de softwares e da análise hipotéticodedutiva, para interpretação e análise dos conteúdos dos mapas, esses que foram os principais recursos de produção do conhecimento geográfico para esta pesquisa.

\section{REPRESENTAÇÕES HISTÓRICAS DE MINAS GERAIS}

Dentre o vasto acervo documentário sobre a história de Minas Gerais, os mapas selecionados permitiram analisar as representações históricas dos limites de Minas Gerais nos séculos XVII, XVIII e XIX. Nesta evolução, o conhecimento da abrangência do território mineiro era limitado e as técnicas cartográficas eram imprecisas.

Eram pessoas que vinham de outros países com uma formação acadêmica que permitia a eles confeccionar as cartas a mando de outros superiores do governo. As cartas confeccionadas nesse contexto também não eram de produção exclusiva: muitos eram inspirados em outras produções já conhecidas para aprimoramento do registro da informação que era necessária.

É interessante ver a história com um olhar de ciclo, em que distintas épocas dispunham de diferentes recursos assim como necessidades, voltadas para o tempo cujo reflete suas condições. Evidentemente, os mapas manifestam uma evolução na forma em que foi executado, e técnicas utilizadas para representar determinado conteúdo, correspondente aos anseios provocados por esses profissionais pelo estado de maior liderança. As intensas transformações no Brasil de um contexto colonial para republicano revelam as inquietudes que levam a novas interpretações sobre o território, e prioridades do conhecimento desejado e necessário. 


\subsection{Sistema de coordenadas - meridianos e sua universalização}

Para cartografar, representar o real, é necessário um ponto de referência longitudinal para basear todos os aspectos do mapa. Nisso, um importante item ao estudar e descrever os mapas históricos é o sistema de coordenadas que foram utilizadas, isto é, a latitude e a longitude. Os mapas selecionados para essa produção apresentam meridianos de origem diversos; os que apresentam maior destaque são: Ilha de Ferro, Rio de Janeiro e Paris. Os meridianos de origem se referem a locais que os cartógrafos utilizaram como referência para mapear e elaborar o sistema de coordenadas do mapa. Estes sistemas possuem diferenças que influenciam diretamente na precisão do mapa. Como sendo meridianos, a longitude era o valor que mais variava, sendo a que apresenta maior diferença de um mapa para o outro.

Segundo Seeman (2013), o primeiro meridiano de origem foi estabelecido por Ptolomeu no século II nas Ilhas Afortunadas, que hoje corresponde as Ilhas Canárias como referência e também como limite de um mundo até então conhecido. Depois do avanço do conhecimento sobre as Américas colonizadas pelo resto do mundo, o Papa Espanhol Alexandre VI estabeleceu em 1493 um ponto de demarcação a oeste das Ilhas de Cabo Verde para dividir as terras espanholas e portugueses do "Mundo Novo".

Após esse fato, surgiu o "Atlas Histórico do Brasil 500 anos", que apresenta certa maleabilidade das linhas de referências e apresenta oito meridianos de Tordesilhas entre os anos de 1495 e 1688. A França, por volta de 1686, fixou um meridiano de origem na Ilha de Ferro e nas Ilhas Canárias. Na época, esse meridiano de marcação tinha marcada uma ideologia geopolítica por trás de sua criação, porque na época, os navios franceses apenas foram autorizados a atacar os navios espanhóis e portugueses nas águas a oeste dessa linha e ao sul do Trópico de Câncer; por isso, o interesse em mover o meridiano de referência para leste para poder atacar mais próximo da Europa (SEEMAN, 2013).

Além dos meridianos que eram considerados universais na época, também existiam outros que eram utilizados de maneira local por alguns países. Com o nacionalismo forte no século XVII cada país tomou para si um meridiano de origem. Dessa forma, surgiram vários meridianos de origem de importantes capitais como: Londres, Washington, Paris, Filadélfia. Até mesmo o próprio Brasil tinha um meridiano de origem fixado no observatório Castelo no Rio de Janeiro. A existência de vários meridianos de origem tornava a navegação confusa (SEEMAN, 2013).

A partir dos anos 1800 começou a ser pensado na ideia de um meridiano de origem universal para todos os países. Em 1871, por ocasião do Primeiro Congresso Internacional de Geografia em Antuérpia na Bélgica, foi recomendada a adoção do Observatório de Greenwich como meridiano zero para todas as longitudes e todas as cartas marítimas para os próximos quinze 
anos. Após isso em 1884 houve uma conferência internacional que definiu Greenwich como meridiano universal.

\subsection{Século XVII}

A análise da evolução dos limites territoriais, das dinâmicas nas representações e identificação da posição e influência do estado como um todo se inicia com a descrição de dois mapas do século XVII, para compreensão de como era representado o específico recorte do território brasileiro antes de possuir Minas.

O mapa a seguir foi elaborado por Nicolas Sanson d'Abberville em 1656, geógrafo e francês (MAPA, 2016).

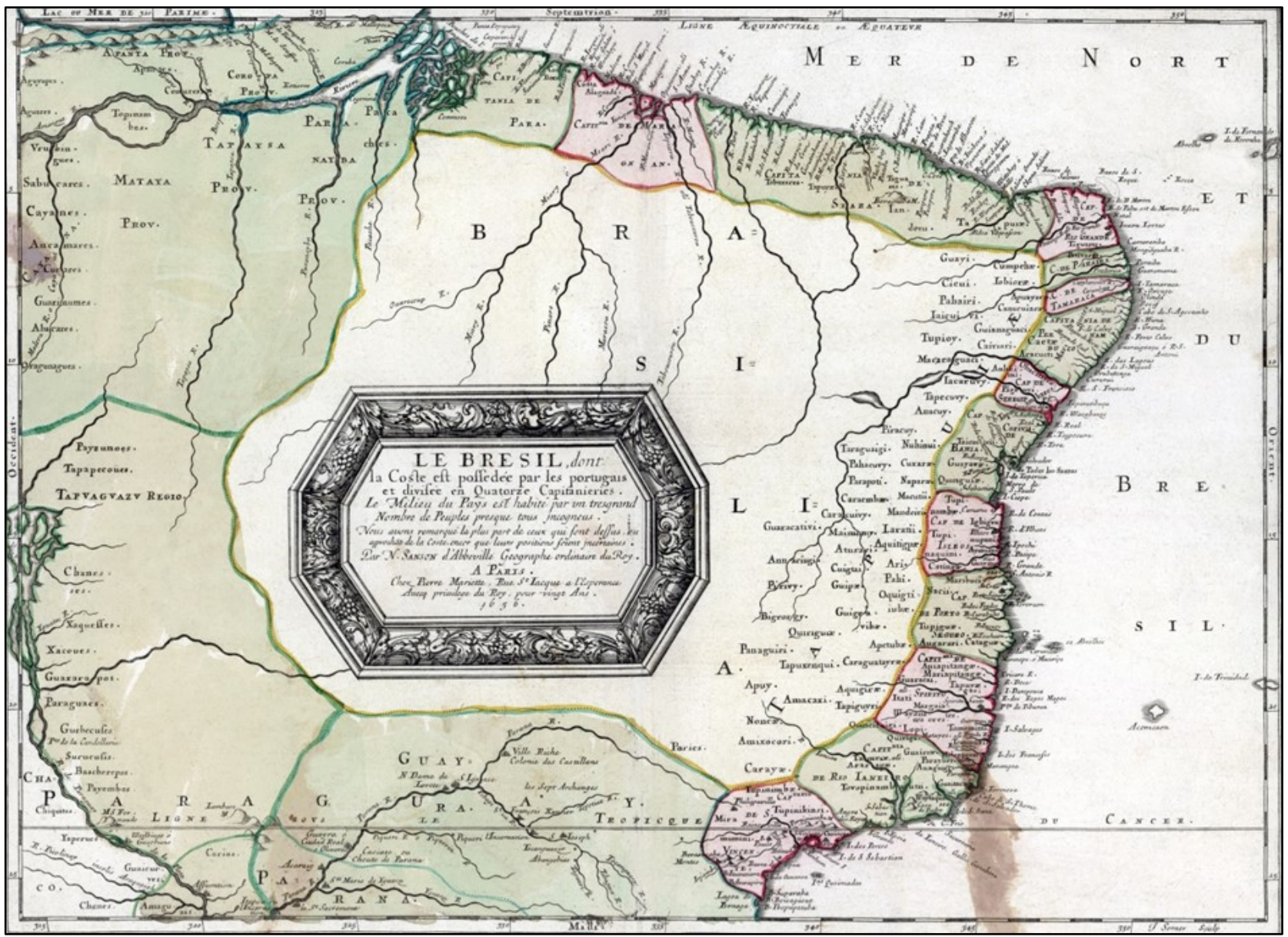

Figura 1 - Le Bresil 1656

Fonte: Guia geográfico história do Brasil [21--].

Nessa produção se observa que a representação do Brasil foi feita ao longo da costa, onde começou de fato a apropriação de terras pelos colonizadores. São destacados os limites territoriais e a hidrografia interna principal. 
Neste mesmo século, Blaeu produzira uma carta da costa brasileira (figura 02). Joan Blaeu (1598-1673) influente cartógrafo holandês foi nomeado como cartógrafo oficial da Companhia das Índias Orientais Holandesas em 1638, o que deu a ele acesso as cartas das rotas marítimas para as índias, fazendo com que suas produções cartográficas possuíssem melhor precisão (BROTTON, 2014). O site da Biblioteca Digital Mundial indica que o mapa foi publicado em 1680.

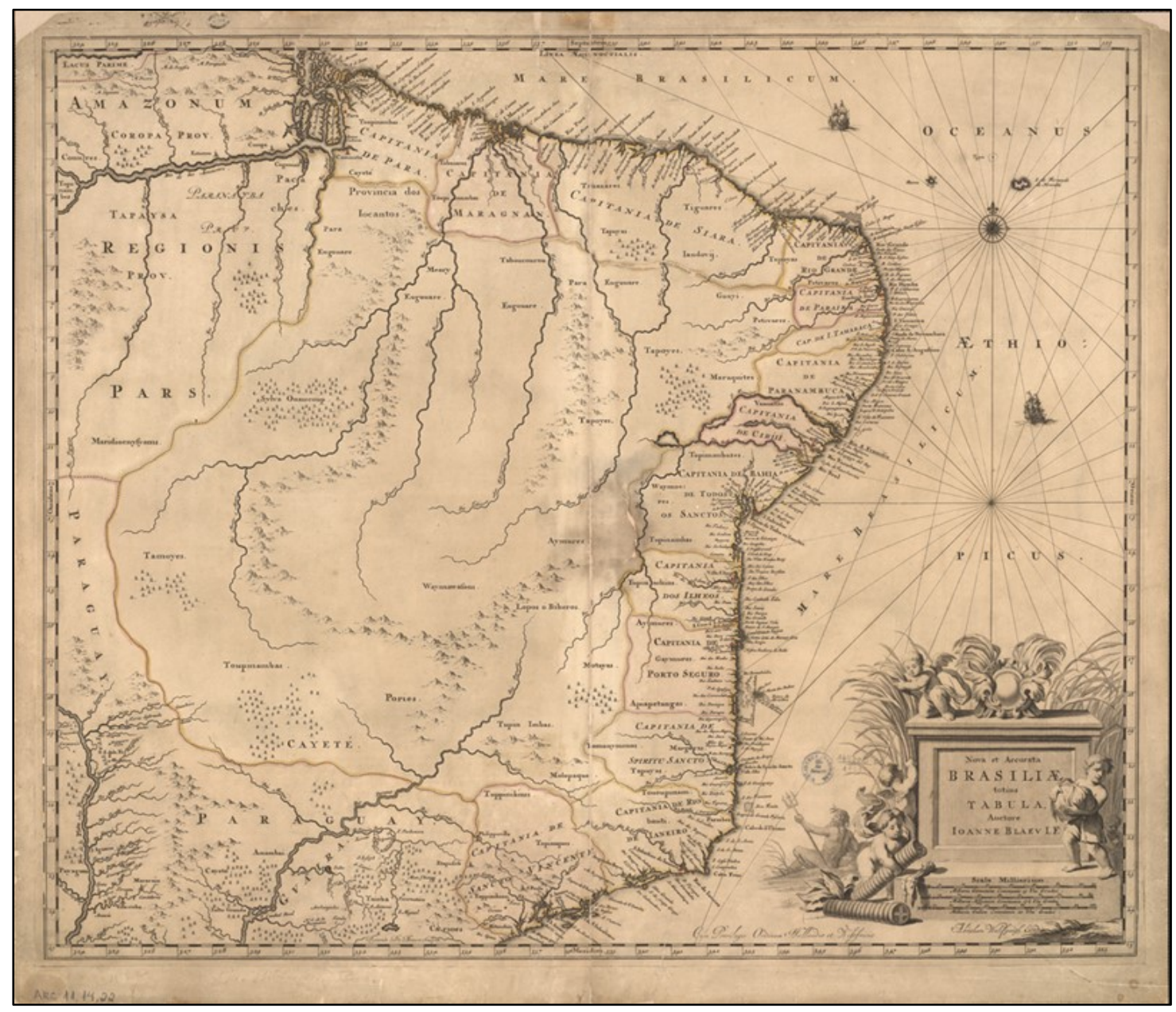

Figura 2 - Brasiliae.

Fonte: Biblioteca Mundial (2015).

As semelhanças que se observa nas cartas de Sanson e Blaeu é a representação dos limites das capitanias, o arquipélago de Marajó (atual estado Pará) - enfatizado em muitas produções cartográficas da época por ser um importante meio de referência da época -, os principais portos da costa brasileira, a hidrografia e alguns detalhes do relevo, que fora representado com topos de morro. O que diferencia na carta da Blaeu, é uma preocupação maior em representar o relevo e a vegetação, com pequenos arbustos. É interessante observar o traçado dos meridianos a partir da referência marítima, evidenciando a influência posta pelas cartas de rotas para as índias, assim como a representação de barcos que se "aproximam" da costa. Já no mapa de Sanson, a referência cartográfica enfatizada é o trópico de câncer. 


\subsection{Século XVIII}

O século XVIII foi marcado pela descoberta do ouro em Minas Gerais e com ela, foram surgindo as primeiras vilas da capitania que foram se instalando com as primeiras populações. Em 1709 a coroa assumiu o controle das Minas Gerais, que até então fazia parte do território paulista e só em 1720 conseguiu sua autonomia. Pelos conflitos sociais, administrativos, eclesiásticos, de interesses geopolíticos pela dominação e controle do território e ainda do ouro com a cobrança do quinto, a coroa portuguesa necessitava cada vez mais de registros cartográficos da região das minas do ouro.

Nesse contexto, surge José Joaquim da Rocha, que foi nomeado pela coroa para levantar dados cartográficos, topográficos e geográficos da Capitania de Minas Gerais, e aqui se estabeleceu por volta da segunda metade do século XVIII.

\subsubsection{José Joaquim da Rocha}

De acordo com Resende (1995), José Joaquim da Rocha era um perito de assuntos estratégicos e de segurança da capitania mineira; conhecedor do território de Minas Gerais fez um profundo levantamento geográfico sobre as suas regiões. Há na pesquisa sobre a bibliografia de José Joaquim da Rocha muita incerteza sobre a procedência das informações, apesar de serem encontrados dados sobre. Nasceu por volta de 1740 em São Miguel da Vila de Souza, no Bispado da Extremadura. Chegou a Minas por volta de 1763-1768 e aí ficou até morrer em 1804. Presidiu em Vila Rica e trabalhava como militar.

Furtado (2009) menciona um envolvimento direto de José Joaquim da Rocha com a Inconfidência Mineira. Foi autor de alguns dos mapas de população que foram obtidos por Tiradentes, o que configurava uma informação estratégica vital nas mãos de um inconfidente, e tempos depois admitiu ter entregado o(s) mapa(s), porém sem nenhuma malícia. Não chegou a ser considerado um réu apesar de estar claro que ele tinha algum envolvimento com os inconfidentes.

Como cartógrafo, Rocha exercia uma atividade primordialmente militar para ações estratégicas no que tange ao domínio territorial das minas do ouro, tarefa significantemente importante em sua administração e controle espacial. Resende (1995) complementa a análise acrescentando a importância dos mapas nesse contexto histórico- militar: "Traçar estratégias militares ou avaliar as dificuldades de domínio sobre o território conquistado foram tarefas para as quais, desde, pelo menos, o século XV, a confecção de mapas mostrara, continuamente, sua utilidade" (RESENDE, p. 20, 1995).

Por este fator citado acima e por outros que compunham um caráter geopolítico da região das minas do ouro, a preocupação com a cartografia mineira surgiu desde muito cedo, antes mesmo 
que outras regiões do estado brasileiro. José Joaquim da Rocha conhecia com propriedade o território mineiro e, além dos mapas, tem muito material documentado sobre a região. Também utilizava de testemunhos orais e outros tipos de registros documentais da época (RESENDE, 1995).

Entre os mapas de Rocha, destacam-se cinco principais obras, das quais datadas por volta do ano de 1778. Um que corresponde a Capitania das Minas Gerais, e os demais que correspondem as comarcas que compunham a capitania, entre elas: Rio das Mortes, Rio das Velhas, Vila Rica e Serro Frio. Segundo Furtado (2009) José Joaquim da Rocha, para a sua época, empregou as técnicas mais modernas, como podem ser vistas em seus mapas: convenções geográficas esquemáticas, normas cartográficas que vinham se universalizando na época, e busca mais presente entre o real e sua representação.

Segundo a visão de Furtado (2009) sobre a representação cartográfica de José Joaquim da Rocha, ele, por vir a conhecer de forma aprofundada a área das minas gerais tomando medidas de distância entre algumas localidades, acabou por representar áreas de melhor qualidade e que se destacaram como importantes mapas para representar a área. E mesmo assim, como pode ser visto na figura 03, houve alguns erros de direção e de projeção na representação da área, que serão analisadas posteriormente. Quanto às escalas de José Joaquim da Rocha, estas apresentam uma devida proporção entre a representação e o espaço real, considerando os métodos disponíveis para determinada época.

Houve boa preparação de José Joaquim da Rocha em reproduzir em sua produção de mapas as técnicas mais modernas para a época, por ter sido treinado nas transformações da cartografia e da geografia implementadas em Portugal, a partir da primeira metade do século XVIII. Há alguns padrões na linguagem esquemática e universal nas produções cartográficas como os mapas coloridos em tom sépia, estradas tracejadas, campo coberto por árvores, representação de núcleos urbanos nos mapas. Sobre a cartografia e suas intencionalidades, Furtado (2009) complementa: “Cartografar um território não é uma operação neutra, cuja objetividade estaria assegurada pelo uso de técnicas as mais aperfeiçoadas.” (FURTADO, 2009 p. 179).

Rocha estabeleceu seus mapas a partir da referência do meridiano de Ferro, com o objetivo de utilizar uma linguagem mais universal na produção de seus mapas por visar um público mais amplo ou internacional. Utilizava na época a escala em léguas, ou seja, uma légua correspondia a 6 quilômetros. É possível perceber após em seus mapas a distribuição das vilas, paróquias, capelas, fazendas, a rede hidrográfica, a vegetação e o relevo também são considerados. 


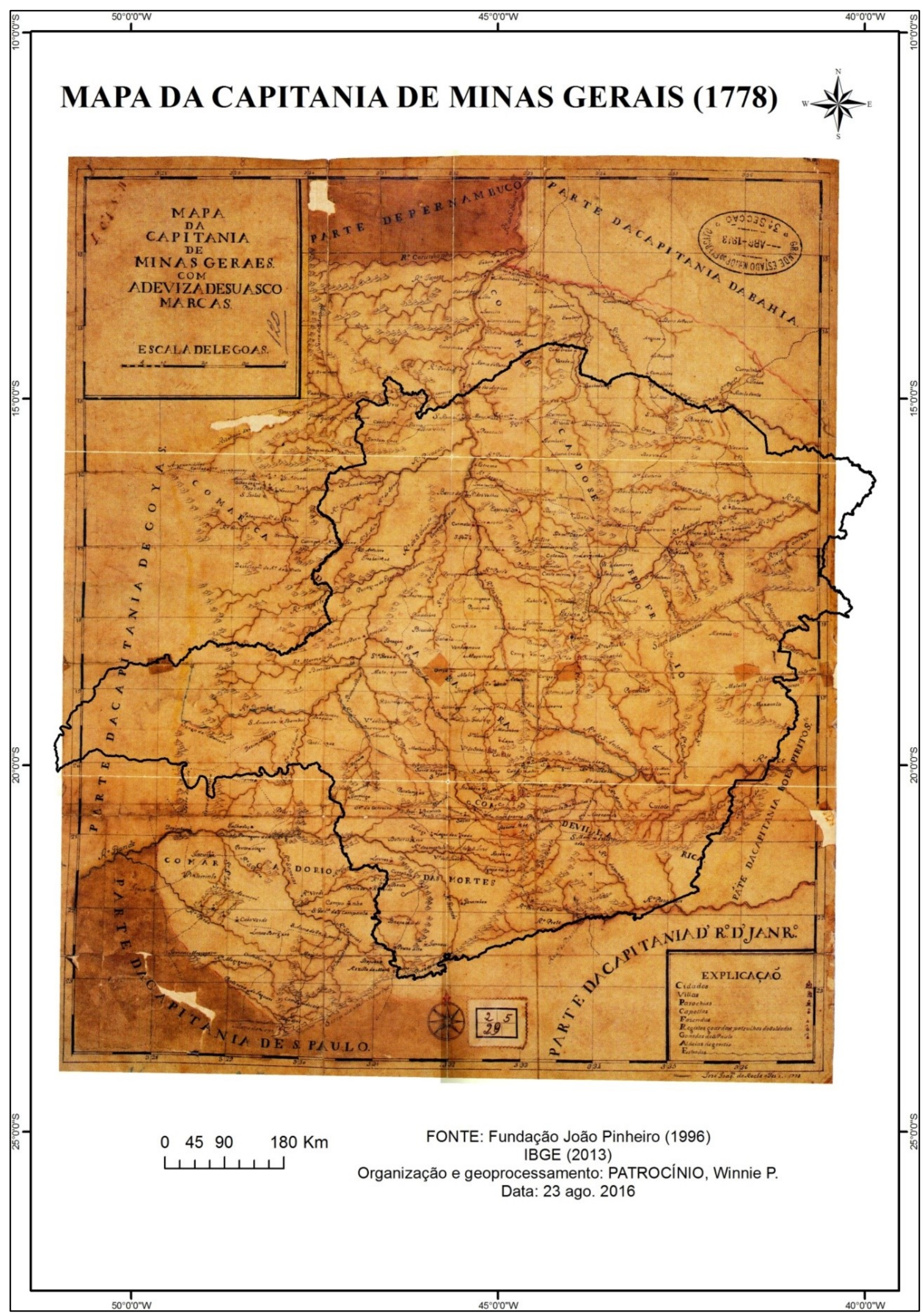

Figura 3 - Mapa da Capitania de Minas Geraes. Georreferenciamento do mapa de 1778 em relação ao limite atual de Minas Gerais. Fonte: Elaborado pelas autoras (2016). 
$\mathrm{Na}$ figura 04 têm-se os mapas das quatro comarcas da Capitania de Minas Gerais elaborados por Rocha, por volta do ano de 1778 (Sabará, Serro Frio, Rio das Mortes e Vila Rica). Como já foi descrito as suas principais técnicas, é importante frisar a superposição de camadas de informação pelo software ArcGIS do atual limite da Unidade da Federação com o que foi delimitado em 1778, que demonstrou erros notórios de projeção nessas áreas. Podemos ver no que era definido como região nesta época, territórios pertencentes a atual área do triângulo mineiro que não pertenciam à Capitania de Minas Gerais e sim à Capitania de Goiás.

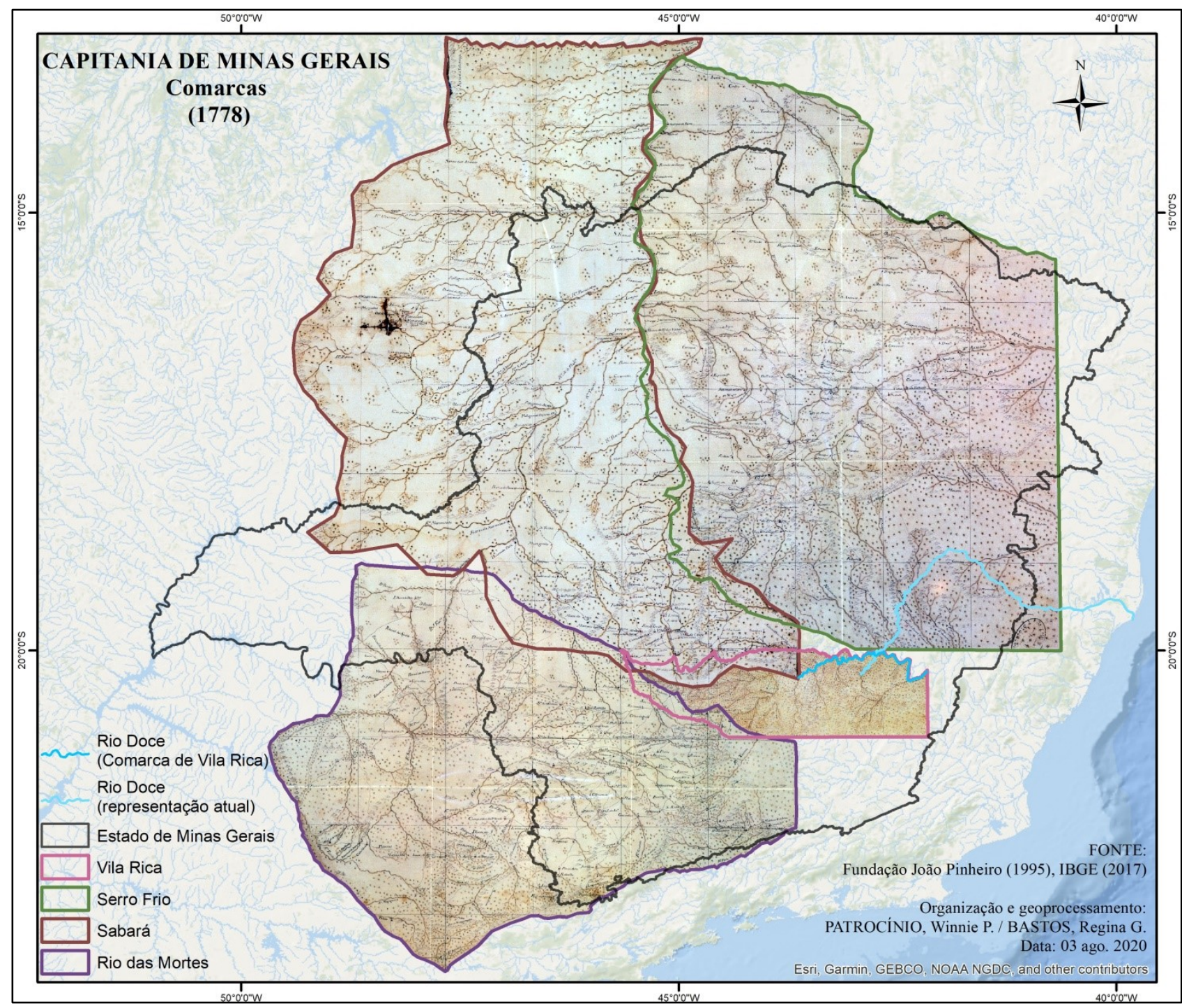

Figura 4 - Comarcas de Minas Gerais delimitados e georreferenciados de acordo com o meridiano de Greenwich (1778). Fonte: Elaborado pelas autoras (2016).

Segundo Castro (2013) no século XVIII os mapas apresentavam muitas inadequações, inclusive na projeção, portanto havia problemas com a precisão das escalas e medições longitudinais. Nota-se na análise dos mapas de Rocha, tanto os das quatro comarcas quanto o da Capitania de Minas Gerais desvios de projeção para a região noroeste, sudoeste, norte. É perceptível também a defasagem da representação cartográfica da Zona da Mata e poucas informações 
encontradas sobre o Espírito Santo. Provavelmente pela presença de uma mata densa, Rocha não fez expedições suficientes na região. Aliado a isso a região possuía uma grande presença de indígenas.

É possível notar que Rocha também não foi preciso na projeção das comarcas. Feito o corte do território das comarcas, é visto que elas poderiam levar a uma leitura individual de cada comarca comprometida, tanto pela coroa portuguesa, pelos militares, assim como para os próprios governantes do estado mineiro.

Como se percebe no mapa da comarca de Vila Rica, o rio Doce corre de leste para oeste; porém, quando se observa a posição do rio na sua representação mais atual, ele parte de sua montante em Santa Cruz do Escalvado (a leste) e segue na direção noroeste, passando pelo atual município de Governador Valadares e depois segue na direção sudoeste, fatos que provam a imprecisão de seus mapas, os erros de projeção e de localização. É possível pensar que a precisão e informações de aspectos geográficos de determinadas áreas era mais importante do que de outras, para fins geopolíticos, administrativos, econômicos, entre outros.

\subsubsection{Manuscrito e cartas por José Joaquim da Rocha}

No processo de desbravar as terras da Capitania de Minas Gerais, seguia-se o de organizar a gestão do território. Por trás desse processo, tem-se um conjunto de operações menos visível, tendo em comum o fato de assegurarem poder ao estado e outras formas ou possibilidades de fortalecer o domínio sobre um território. Nessas atividades estão incluídas: as viagens de autoridades coloniais, as expedições científicas, os inquéritos locais para a avaliação das possibilidades de renda real, a organização de estatísticas, a elaboração de roteiros de caminhos, a descrição de viagens de reconhecimento de novas regiões, a abertura de caminhos e estradas para o controle administrativo, financeiro e militar, entre outros (RESENDE, 1995); a fim de conhecer para controlar e dominar um território com auxílio da cartografia militar para a reafirmação de poder.

As cartas e os escritos de Rocha se enquadram no amplo referencial formado pelas operações de conhecimento que produzem saberes estratégicos na consolidação do Estado Moderno e, para Portugal, era a garantia de domínio em terras ultramar (RESENDE, 1995).

\subsubsection{Mapa anônimo 1800}

O mapa denominado "Planta geral da Capitania" não possui registro de autoria e é aqui descrito para uma comparação de métodos de registro utilizados. O mapa foi realizado em um período próximo aos elaborados por Rocha (1778), porém com técnicas que apresentam diferenças 
significantes e inovadoras. Apesar da semelhança no que se refere à escala e contorno do estado, nessa planta não possui demarcações de fronteiras com os outros estados, somente a nordeste em encontro com Bahia que se observa uma linha tracejada e pontilhada separando Minas de "Capitania da Bahia".

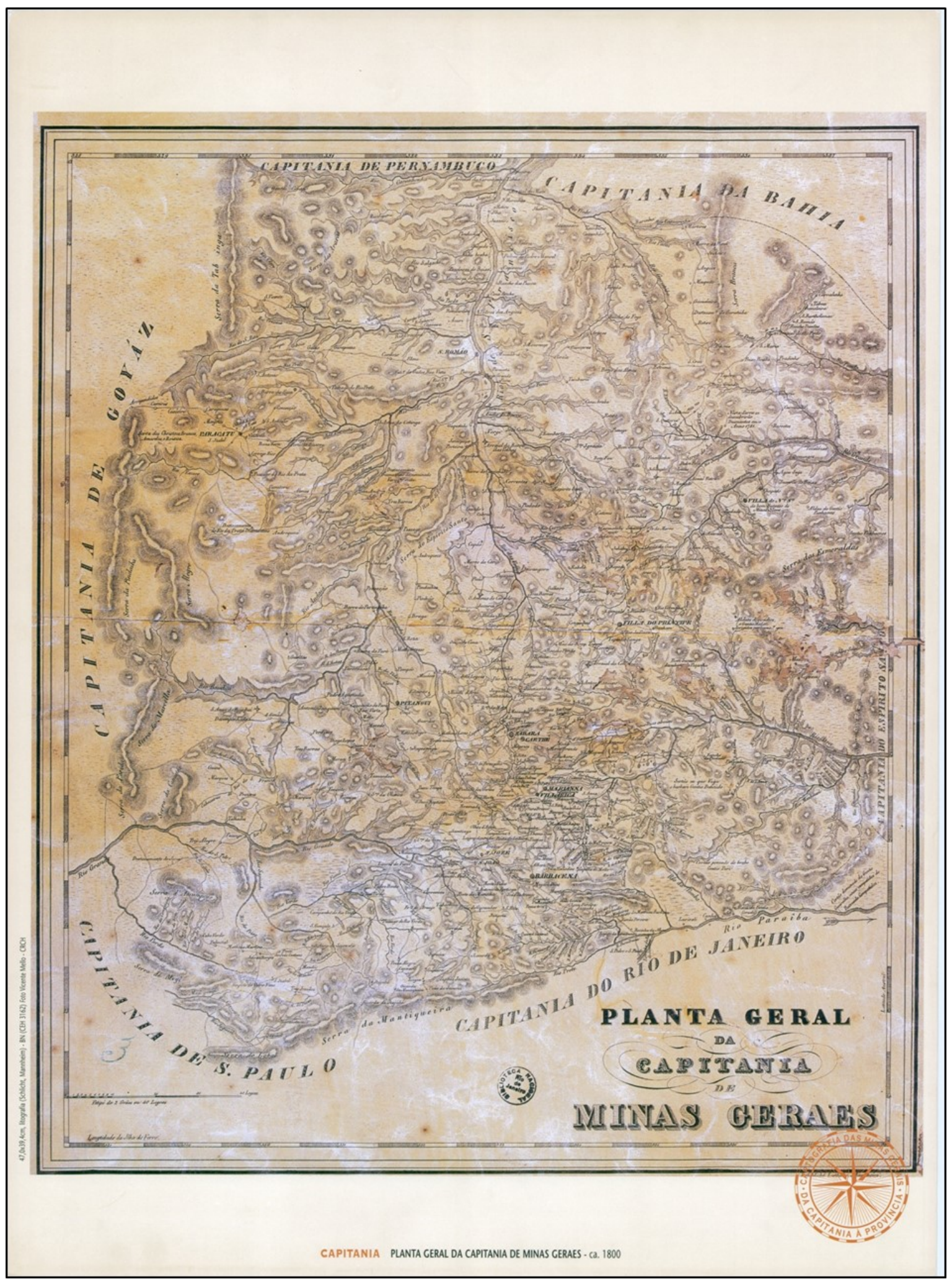

Figura 5 - Planta Geral da Capitania de Minas Gerais.

Fonte: Arquivo Público Mineiro. 
O autor deste mapa apresenta melhor noção de escala, ao representar o Rio São Francisco com mais expressividade ao longo de sua extensão, o Rio Bambuí, Rio Grande e Rio Doce, assim como seus afluentes. O que torna a visualização mais clara nessas escalas da hidrografia é a representação do relevo. Na carta de Rocha de 1778, é expresso o relevo com topos de morro; diferente do autor da "Planta geral da Capitania", que utiliza hachuras, técnica que demonstra a altimetria em níveis diferentes: a hachura mais escura com mais traços curtos, revela topos de morro mais expressivos, e as hachuras mais claras com traços maiores, relevos com menos declividade, próximos sendo em torno de rios. Exemplo claro é a Serra da Mantiqueira ao Sul do estado e a Serra da Marcela, que "cercam” o estado ao eixo leste, junto com a Serra da Pindaíba.

A escala dos dois mapas é expressa em léguas. A longitude da Ilha de Ferro e latitude Austral revelam os meridianos e paralelos do mapa anônimo.

Santos, Cintra e Renger (2013) revelam que o mapa em questão possui mais precisão referente ao próprio meridiano de origem, quanto o mapa de Rocha (1778) possui erros de até $1^{\circ}$ de diferença.

\subsection{Século XIX}

Como visto na história, no século XIX Minas Gerais recebe dois eventos mais marcantes: a incorporação da região do Desemboque no território, conhecido como nariz de Minas, hoje regionalizado como triângulo mineiro; e a introdução de novas tecnologias para explorar as riquezas minerais, de forma a recuperar a economia aurífera obtendo maior aproveitamento das riquezas. $\mathrm{O}$ barão de Eschwege esteve presente no estado nesses dois fatos importantes: contribuiu para a formalização do limite com o estado de Goiás assim como renovou técnicas de mineração. Devido sua importância na história, o mapa selecionado do século XIX foi o confeccionado por cujo será apresentado um breve histórico.

\subsubsection{Eschwege e a incorporação do triângulo mineiro}

Wihem Ludwig von Eschwege, formado em ciências naturais na Alemanha, foi designado para o Brasil pela coroa portuguesa para melhorar o rendimento da produção aurífera. Aproveitou suas viagens até o estado para confeccionar mapas e realizar levantamentos de forma obter dados cartográficos (SANTOS; CINTRA; RENGER, 2013). Em 1821 elaborou um mapa que serviu de base para que fosse confeccionado um novo, que se intitula "Mappa da Província de Minas Geraes", atualizado por Luiz Maria da Silva Pinto em 1826. Renger e Gomes (2013) dissertam que a obra foi elaborada pela demanda de obter um mapa geral para que se tenha: "reconhecimento de rios, 
construção de estradas e pontes, litígios de limites, prospecções minerais e roteiros de viagem. (p. $3) "$.

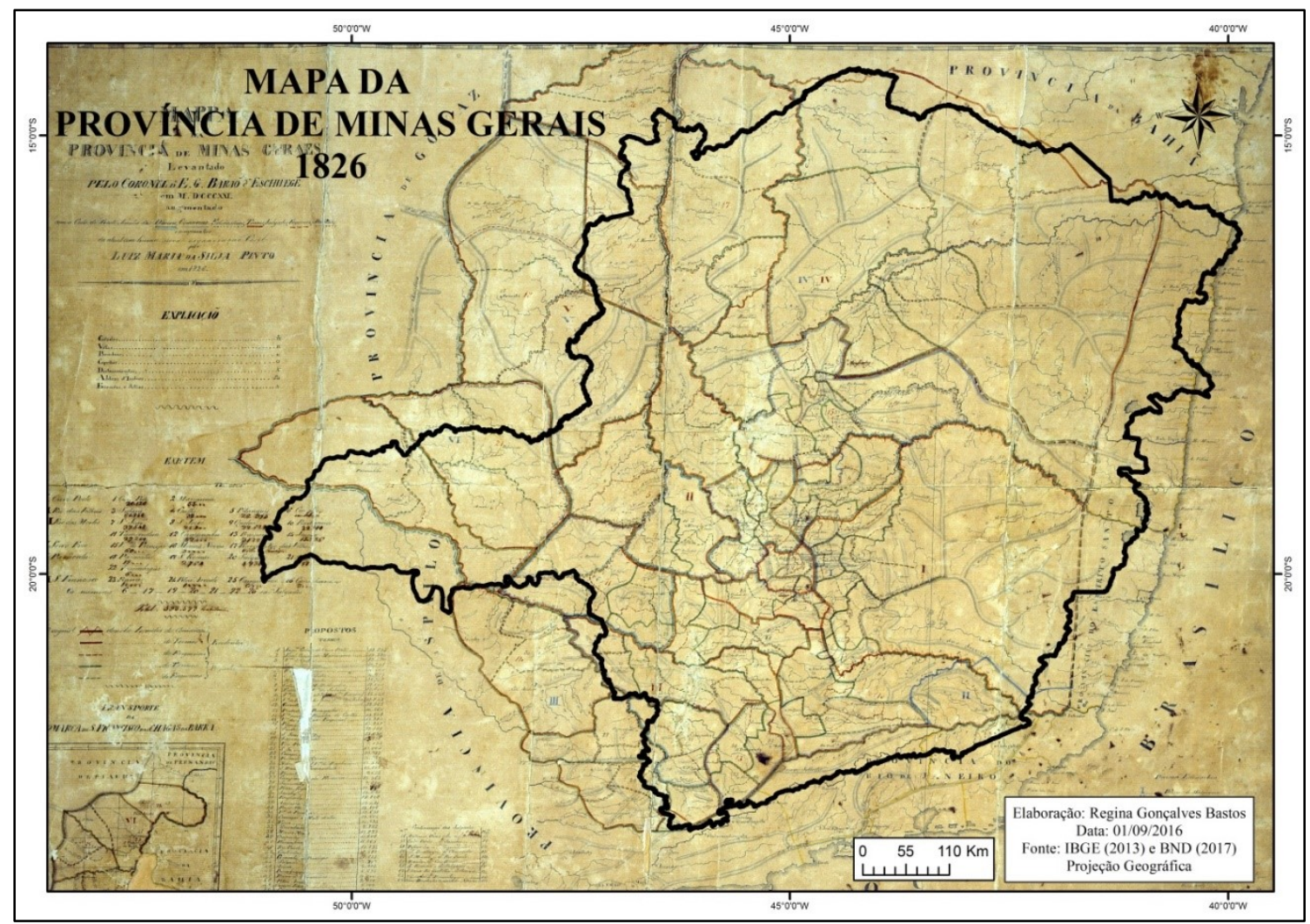

Figura 6 - Mapa da província de 1826.

Fonte: Elaboração das autoras (2016).

A carta abrange também a Província do Espírito Santo e a Província do Rio de Janeiro, com a costa leste representada com hachuras, demonstrando o desaguar do Rio Doce que passa por Espírito Santo. A drenagem principal foi representada com mais ênfase assim como seus meandros.

O que mais destaca na carta é a preocupação em registrar limites territoriais, em que há divisão das comarcas, termos e freguesias (existentes e propostas). A preocupação com escala no que se refere à drenagem principal, não é muito evidente como nos mapas do século XVIII; apenas os meandros que demonstram mais variação, tanto a drenagem principal como os afluentes.

É necessário ressaltar que os cursos d'água mais expressivos não estão evidentes como nas outras cartas, pois neste mapa, os limites territoriais são evidenciados se apropriando da morfologia das águas, portanto mais preocupado com as definições de limites territoriais. É interessante observar como os rios sempre foram um importante limitador de território. Exemplo evidente é o próprio triângulo mineiro, que se delimita com dois rios (Rio Grande ao sul e Rio Paranaíba ao norte).

O que sugere a preocupação em elaborar um mapa com os limites da administração interna do estado é o próprio destaque que o estado passa a assumir com a consolidação de seus limites com 
outros estados, assim como o aprimoramento da mineração e elaboração de novas formas de renovar a economia. Gomes (2013) consta as ambições que uma carta possui para sua produção:

Evidentemente, a carta geral da província não seria instrumento de tradução imediata ou observação visual direta desses problemas. Ela responderia fundamentalmente à necessidade do poder público de dar visibilidade e transparência ao território administrado, de tornar identificáveis e conexos, por intermédio de uma nova imagem-síntese, os espaços desarticulados, impenetráveis, litigiosos. (GOMES, 2013, p. 117)

Com o georreferenciamento da carta é perceptível o erro em toda porção oeste de Minas. O leste limítrofe inclusive com o estado de Rio de Janeiro, ao entorno do Rio Paraíba, atual Paraíba do sul, possuem proximidade com o limite atual, assim como a região limítrofe com Bahia.

\subsection{Processo de modernização do estado de Minas Gerais}

A partir do final do século XIX, houve grandes transformações nas terras mineiras, assim como em todo o contexto da modernização. As técnicas cartográficas são aprimoradas e os mapas ganham outro sentido. Como já dito, os mapas são instrumentos de poder, que muitas vezes é utilizado para fins específicos, vinculados fortemente com interesses políticos. Desse modo, o crescimento populacional que Minas Gerais enfrentou, promoveu interesse nas informações relacionadas ao CENSO, para que se tenha um controle do próprio fenômeno. O mapa produzido pelo Serviço de Estatística Geral da Secretaria da Agricultura, Indústria, Terras, Viação e Obras Públicas; a seguir, revela essa condição (Figura 7).

Antes de observar as características principais do mapa dentro do limite territorial mineiro, atualizado, faz-se a observação do que a carta compõe nas extremidades. Ao lado direito, observase uma série de listas nominativas, em que há a listagem de importantes acontecimentos históricos para o estado, como por exemplo, a criação da Capitania de São Paulo e Minas Gerais (1709), e a primeira divisão administrativa e judiciária do estado (1891). Há também quantificações do estado em reservas florestais, altitude, serviços de transporte e ensino. A lista mais extensa que se apresenta é a de municípios, listando 215.

$\mathrm{Na}$ legenda, a escala é apresentada já em centímetros, e as hierarquias urbanas definidas: estado, cidades/sedes de comarcas, cidades/sedes de termo, villas (sem fôro), sedes distritais, povoados, colônias e núcleos coloniaes; e os limites, em uma informação linear. Observa-se a preocupação em representar as vias férreas em espessura e estágio de construção.

Além de todos esses diferenciais, a carta representa também a nova capital, Belo Horizonte, com limites bem definidos e a característica principal de centro geométrico. Revela a classificação do centro como urbana e a chamada do que está fora da avenida do Contorno, a zona suburbana, revelando a expressividade das definições hierárquicas nesse novo contexto histórico de 
definição e produção das variáveis quantificáveis do território. A representatividade da capital é expressa, mais uma vez, nas listas explicitadas, cujas informações mostram inclusive, os principais edifícios da capital.

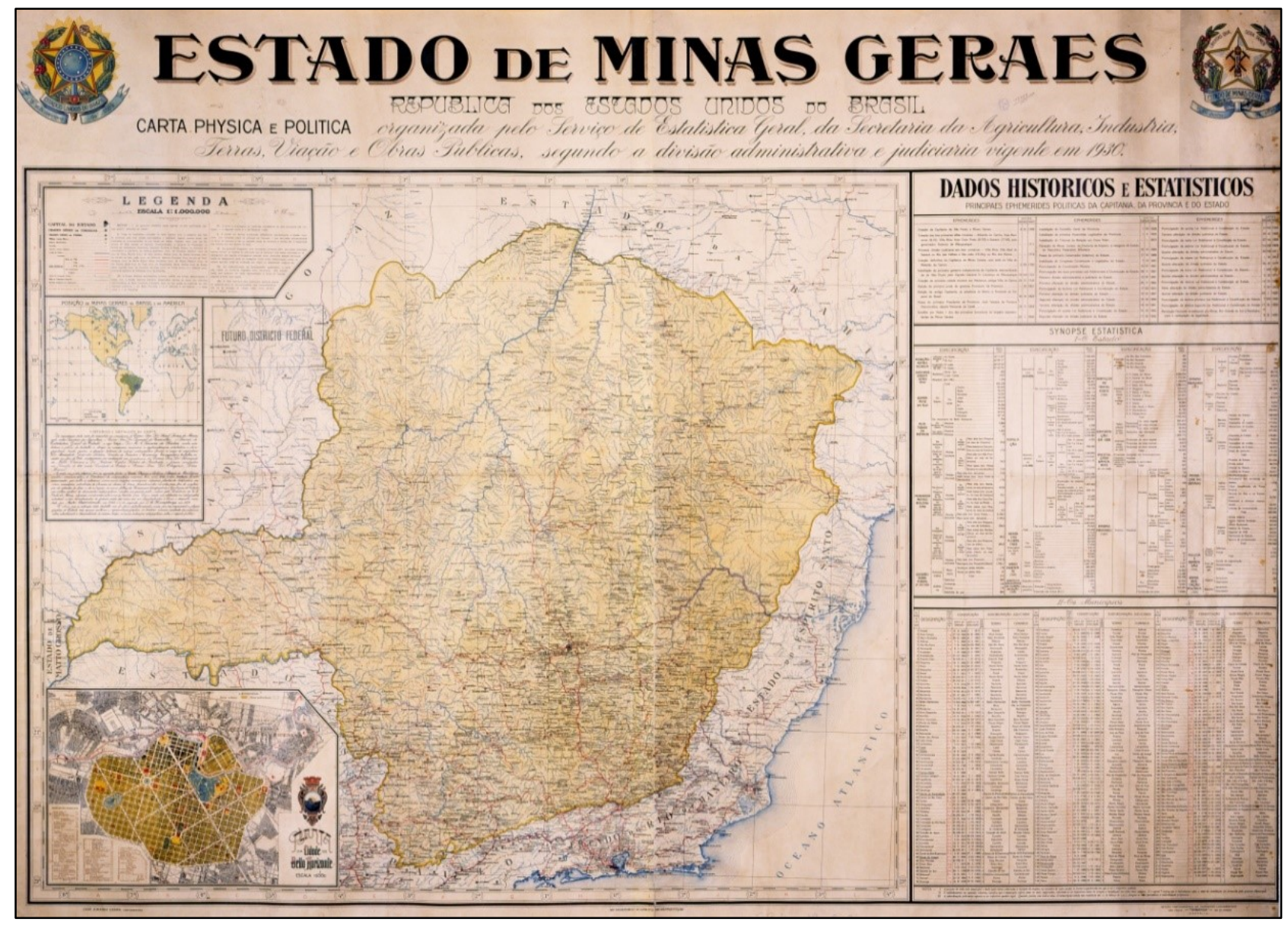

Figura 7 - Estado de Minas Gerais.

Fonte: Biblioteca Digital Luso-Brasileira.

Por fim, se tratando diretamente dos elementos visuais que adentram o limite territorial do estado, percebe-se que ainda se faz presente a hidrografia como um importante elemento de referência. Até mesmo porque os corpos d'água foram um importante critério para avaliação do antigo Curral del Rei como a melhor região para se instalar o principal centro do estado. A via férrea também é bem expressa no que diz as cores e a espessura do traço utilizado.

É interessante observar que, mesmo com os limites bem definidos, as cidades estão concentradas nas regiões que deram origem às primeiras divisões territoriais: as comarcas. As terras nas porções do triângulo e norte de Minas apresentam um caráter esvaziado. Vias de acesso indicada para esses vetores o que pode revelar um futuro crescimento populacional e econômico, mas isso acontece tardiamente. As relações que aparentemente são mais bem expressas são aquelas ao sul do estado, entre porções extremas do estado de São Paulo, vários vínculos com Rio de Janeiro e alguns ao sul do Espírito Santo. 


\section{CONSIDERAÇÕES FINAIS}

A busca dos fatores responsáveis para a constituição histórica de Minas Gerais é evidenciada na pesquisa através dos mapas. A Cartografia é a ciência que, de forma geral, realiza a produção de mapas, que possuem um grande potencial revelador de condições espaço-temporais.

Desta forma, observa-se que: a Cartografia revela, constantemente, os interesses políticos determinados pelo contexto histórico.

Percebemos que ao longo do século XVII, os mapas utilizados representam os cursos d'água e alguns portos que, inicialmente, revelam a influência marítima para a troca de mercadorias, e adentro aos territórios.

No século XVIII, auge da produção cartográfica de Minas Gerais, assim como a produção de sua historicidade, os mapas revelam diversos aspectos os quais foram considerados no ciclo do ouro: os cursos d'água detalhados - nos rios que se encontram significativos tipos de minerais preciosos -, a divisão político-administrativa do momento, as comarcas; e regiões com característica física específica, como a zona da mata, que revela a dificuldade dos exploradores em adentrarem aquela região.

No século XIX, tem-se a representação do estado, como novidade, a demonstração de uma preocupação maior com os limites políticos administrativos. Esse exemplo vai se suceder com a melhoria da representação dos elementos composicionais dos mapas e o próprio sentido de uso e exploração daquele território sendo transformado.

Evidentemente, no século XX, com a revisão historiográfica do estado, há o modelo econômico transformado e enriquecido com outras áreas de desenvolvimento. Como consequência, as taxas de imigração crescem rapidamente e, a junção do desenvolvimento do trabalho com a necessidade da mão-de-obra, aliada a preocupação com a quantificação desses dados para melhor controle territorial, o mapa utilizado para exemplificação desse século contém listas que relatam dados que permaneciam em constante transformação e crescimento.

Assim sendo, esta pesquisa tem o potencial em contribuir para os estudos da história de Minas Gerais, visto que a conta de forma dinâmica, considerando aspectos essencialmente territoriais; e, principalmente, a evidência da ciência cartográfica como uma importante contribuidora para a produção do conhecimento geográfico e as infinitas possibilidades de recursos e manipulação de dados e suas interpretações. 


\section{AGRADECIMENTOS}

Direcionamos nosso agradecimento À Fundação de Amparo à Pesquisa do Estado de Minas Gerais - FAPEMIG, e ao Programa de Bolsas de Iniciação Científica da PUC Minas, pelo financiamento da pesquisa.

\section{REFERÊNCIAS}

BROTTON, J. Uma história do mundo em doze mapas. 1. ed. Rio de Janeiro: Zahar, 2014. 616p. CASTRO, J. F. M. Georreferenciamento e cartometria dos mapas da Capitania de Minas Gerais elaborados por José Joaquim da Rocha em 1778 e 1793. Sociedade \& Natureza, Uberlândia, v. 25, n. 3, p. 581-593, 2013.

FURTADO, J. F. Um cartógrafo rebelde? José Joaquim da Rocha e a cartografia de Minas Gerais. Anais do museu paulista, São Paulo, v. 17, n. 2. p. 155-187, 2009.

GOMES, M. C. A. Representações cartográficas na província: em busca da imagem-síntese. In: RESENDE, M. E. L.; VILlATA, L. C. (Org.). A província de Minas 1. Belo Horizonte: Autêntica, 2013.

IMAGEM nova e precisa do Brasil inteiro / Johann Blaev I.F. Biblioteca digital Mundial. [S.1]: WDLorg, 2015. Disponível em: <https://www.wdl.org/pt/item/1116/> Acesso em: 30 ago. 2016.

LIMA JUNIOR, A. A Capitania das Minas Gerais. 1. ed. Belo Horizonte: Itatiaia, 1978. 142p.

MAPA do Brasil em 1656 por Nicolas Sanson. Guia Geográfico História do Brasil. [S.1]. [21--]. Disponível em: <ww.historia-brasil.com/mapas/nicolas-sanson.htm>. Acesso em: 29 ago. 2016.

RENGER, F. E.; GOMES, M. C. A. Engenheiros alemães na Cartografia de Minas Gerais do século XIX: Eschwege, Wagner, Halfeld e Henrique Gerber. In: SIMPÓSIO LUSO-BRASILEIRO DE CARTOGRAFIA HISTÓRICA. 5., 2013, Petrópolis. Anais... Petrópolis: 2013. p. 1-9.

RESENDE, M. E. L. Geografia Histórica da Capitania de Minas Gerais: descrição geográfica, topográfica, histórica e política da capitania de Minas Gerais. 1. ed. Belo Horizonte: FJP, 1995. $226 \mathrm{p}$.

SANTOS, M. M. D.; CINTRA, J. P.; RENGER, F. E. Origem das longitudes e precisão das coordenadas geográficas dos mapas de Minas Gerais do período 1767-1821. In: SIMPÓSIO LUSOBRASILEIRO DE CARTOGRAFIA HISTÓRICA. 5., 2013, Petrópolis. Anais... Petrópolis: 2013. p. 1-24. 
SEEMAN, J. Linhas Imaginárias na Cartografia: A Invenção do Primeiro Meridiano. Geograficidade. Crato, v. 3, Número Especial, p. 31-44, 2013.

Trabalho enviado em 13/07/2020

Trabalho aceito em 30/09/2020 